\title{
Women Adaptive Capacity in Post Disaster Recovery in Indonesia
}

\author{
Bevaola Kusumasari ${ }^{1}$ \\ ${ }^{1}$ Department of Public Policy and Management, Faculty of Social and Political Sciences, Gadjah Mada \\ University, Indonesia \\ Correspondence: Bevaola Kusumasari, Department of Public Policy and Management, Faculty of Social and \\ Political Sciences, Gadjah Mada University, Indonesia. Tel: 62-274-56-3362. E-mail: bevaola@ugm.ac.id
}

\author{
Received: December 30, 2014 Accepted: January 23, 2015 Online Published: April 30, 2015 \\ doi:10.5539/ass.v11n12p281 URL: http://dx.doi.org/10.5539/ass.v11n12p281
}

\begin{abstract}
With an aim of identifying women coping capabilities in post disaster, the research objective of this paper is to analyze women resilience within the context of four primary sets of adaptive capacities - economic development, social capital, information and communication, and community competence. Such capabilities have enabled women in post disaster situations in Indonesia to adapt to post disaster situations, fostered acquisition of new skill that have enhanced their contribution to family livelihoods and communities, as well as post disaster socio and economic recovery. The paper points at some reason why women have their capability to return to even better life after disaster. It suggests that social capital, economic development, information and communication as well as cultural-based competence provide an effective and sustainable assistance to crisis-affected women. The originality of this paper is that the issue of women being vulnerable to disasters has gained strength in many reviews of disaster research. Nonetheless, based on results of this research, the notion of women vulnerability is discounted. Women resilience is enhanced in an environment that is characterized by robust availability, easy and quick access to resources, which can easily be deployed to reduce the impact of the disaster.
\end{abstract}

Keywords: adaptive capacity, resilience, post-disaster, Indonesia

\section{Introduction}

Disasters are all encompassing and affect everyone and everything without discrimination. A vulnerable location and population contribute to aggravating the adverse effects of a disaster. The section of the population which is vulnerable to disasters includes but not limited to, the elderly, children, women, the illiterate, people of low socio-economic status; those who lack political and social influence; the handicapped, and those who have low socio-economic status (Tierney, Lindell, \& Perry, 2001). These people lack the access to assets, which can reduce the availability of insurance and result in complete losses when a disaster occurs. Unfortunately, poor populations often live in high-risk areas that are low-lying, and close to "floodplains, riverbanks, steep slopes," and have homes that are poorly built. This fact highlights the study of Cortis and Enarson, as quoted in Covington and Simpson (2006) that "ninety-eight percent of those killed and affected by natural disasters come from developing countries, underlining the link between poverty and vulnerability" (p. 19).

Indonesia is a country prone to natural disasters. The areas that are prone to natural disasters are found in nearly all regions of the country, right from the northern tip of Sumatra to northern Papua. Meanwhile, the earthquake that jolted Yogyakarta on May 27, 2006, and Merapi eruption in 2010, are some of the largest natural disasters the province has experienced. Both of these natural disasters inflicted many casualties, especially women, the elderly, and children. In addition to causing many casualties, the two disasters above disrupted livelihoods, wreaked a lot of damage to property and infrastructure.

In this case, the groups which were extremely vulnerable to the impact of disasters were women, children, elderly, and disabled people. They are the most dominant group as victims in the disaster. Physically, women and children are relatively weak, which hampers their ability to avoid and flee disaster-affected areas compared with adult males. As a result, women, children and the elderly become victims of the ferocity of disasters. Nonetheless, regardless of their social, economic, and cultural vulnerability, women have been found to be the most effective group in disaster response, both with respect to prevention and emergency. Women organizing efforts proved very useful in reducing the risk of disaster. Women often times stay at home, hence live in close proximity with the environment where the disaster occurs. This implies that spreading information through 
women is very effective. The question is how to make the information that is delivered both accurate and precise. At the same time, disaster can turn women into resilient individuals in facing difficult and critical conditions. For example women who lost their husbands had to assume responsibilities of becoming household heads, with the implication that they have had to earn a living to sustain their families. Yet, disaster management more often than not pays little less attention to the needs and involvement of women. Once natural disaster recovery is done, many families are poverty-stricken, especially women. Sexual division of labor, has meant that women usually work in the informal sector, on one hand, while on the other hand, women may act as activators or agents of change that can respond to changes in the environment (Shiva \& Mies, 1993). Women have an advantage in understanding and identifying basic needs of the family. To that end, the implementation of disaster risk reduction programs in vulnerable areas in the wake of earthquakes or volcanic eruptions is expected to improve the lives of women. This article discusses economic development, social capital, information and communication, and community competence of the crisis-affected women as a set of adaptive capacities in post disaster recovery.

\section{Research Methods}

This research employed a blended methodology of both qualitative and quantitative methods. The goal of this type of research is to provide "an in-depth and interpreted understanding of the social world of research participants by learning about their social and material circumstances, their experiences, perspectives and theories" regarding a disaster they had previously experienced (Snape \& Spencer, 2003, p. 3). This research is an exploratory case study that concentrates on Wukirsari Village in Bantul District and Sleman District, Yogyakarta, Indonesia. Two villages were chosen based on the type of disaster women experienced and socio cultural characteristics. In Bantul, the selected location for the research is Giriloyo sub-village, Wukirsari, Bantul, which is the center of batik fabric production. This sub-village has a long history in the development of the batik industry. Women in Wukirsari village experienced the earthquake that jolted Bantul district in 2006 and caused the loss of 6000 lives while Sleman has had to cope with the volcanic eruption that occurred in 2010. While the research location for Sleman district is Pager Jurang sub-village, Kepuharjo, which is the center of wedang Uwuh (a traditional herbal drink) and instant ginger industry, which is a form of economical protection women use to support their families.

Two categories of data categories were gathered: primary data and secondary data. Primary data were collected through a survey that was distributed to 80 women, or 30 percent of data from women who have businesses in Cangkringan, Sleman and 133 women, or 10 percent of women who have businesses in Wukirsari, Bantul. The differentiation of the village's socio economic background allowed a more complete portrayal of both the cultural patterns occurring as well as the deeper issues on how women coped with and tried to become resilient to a disaster. In this study, the main respondents are women who have a job and have a personal income from their work. Those are women running small-scale firms that deal in Batik, leather, bamboo crafts, local food production, convenient stores, and handmade souvenirs. In other words, women in this research are women who are economically empowered and have access to resources. On the other hand, secondary data were collected from documents that were published by the government and NGOs and related to the 2006 Bantul Earthquake and 2010 Merapi Eruption. In order to make the critical data obtained from respondents and key informants more comprehensive, triangulation was done. This entailed conducting a series of in-depth interviews and focus group discussions (FGD) after the survey.

\section{Literature Review}

\subsection{Women and Vulnerability}

There is a long history of vulnerability research on identifying population groups which are most likely to experience the adverse effects of drought and other natural hazards or stresses triggered by social, economic or political forces (Cutter, 1996; Mbithi \& Wisner, 1973; Reardon \& Matlon, 1989). Women is one of the groups that are vulnerable to disasters. Most of the reviews suggest that women experience increased vulnerability before, during and after disaster. Women, according to Lambdin and Lambdin (2000) are categorized as a vulnerable population, which reflects the likelihood of being physically or emotionally wounded. It is helpful to understand the ways in which women are vulnerable to disasters; this is due to the fact that women are active and resourceful disaster responders but often regarded as helpless victims. There are many reasons that explain women's vulnerability to disasters. The lack of access to assets can reduce women's availability to insurance and result in complete losses when a disaster occurs. The significance of gender in disaster vulnerability is manifested in several ways. Fothergill $(1998$, p. 11) observes that women are disproportionately represented among those living in poverty, more often the primary care-givers in a family, and are most often the targets of 
sexual and domestic violence, often bear the brunt of disaster hardship given that disaster "strips away the veil" that usually obscures or disguises many social conditions.

The issue of women being vulnerable in disasters has gained increased interest in the last few years, research conducted on this topic shows that women play important roles in all stages of disasters. There is need to identify and prepare vulnerable locations and populations. A vulnerable population is one that is "capable of being physically or emotionally wounded" (Lambdin \& Lambdin, 2000). "Economic, racial/ethnic, and age stratification make some women needier than others before, during, and after disaster, both among and within cultures" (Enarson \& Morrow, 1998, p. 5). Single mothers, elderly women (women have longer life expectancies than men), and women with low socioeconomic status may experience a higher amount of vulnerabilities than, for instance, a married, high socio-economic status woman would. Also, women with children are "likely to experience higher mortality rates in earthquake disasters, and their caregiving roles are intensified rather than abandoned during crisis. It is also true however, that a majority of the vulnerabilities women face are due to "the arrangements of societies that result in their poverty, political marginalization and dependence on men" (Scanlon, 1998, p. 49). A major issue women face during disasters is that they have less access to resources when compared to men, they do not have the strength of large social networks, they do not always have the authority to make major decisions, and, often times, they are forced to work with men (e.g. contractors, insurance agents, etc.) to help recover from disasters who do not want to comply and help women as much or as easily as they would assist other men.

Enarson and Morrow (1998) added that "women's economic vulnerability is often extreme, making them especially dependent upon disaster relief; but power differentials of gender, age, marital status, and family structure, as well as access to transportation affect who accesses the benefits of assistance programs" (p. 6). According to Scanlon (1998), women are treated differently in every stage of a disaster. Initially, women and children are evacuated and men are allowed to stay in the area, and immediately after the disaster has struck, men often times, will leave their families to "assist others and report to emergency agencies". Finally, in the relief and recovery stages, women can be "left out of the relief process and tend to be outside the 'old boys network' and their ideas may be overlooked or perceived as suggestions rather than orders" (p. 46).

Another scholar such White (2007) highlights the fact that women more than men were found to have responded positively to earthquake aftershock warnings on virtually every indicator. Men and women also appear to respond differently in both to the warning and impact phases of disasters. Women more than men, give credence to warnings and want to evacuate in the face of an impending threat. In terms of preparedness behavior, a lot of extant literature also shows that women seek out hazard information more than men. They volunteer and take part in local preparedness programs and in community organizations addressing local environmental or technological hazards more often then men (Fothergill, 1998).

Women's ability to respond and adapt to disasters is a resource that can be used in planning disaster risk reduction programs. People who live in disaster-prone areas instinctively have their own way to respond to catastrophic events (Adger, Brooks, Bentham, Agnew, \& Eriksen, 2004). This is because both sporadic and regular disastrous events require communities to be able to respond and adapt to disasters. This takes the form of a social system that is agreed and serves as a guideline in running their lives. The social system forms through social interactions, which grow and evolve based on the value agreed by all members of the community. However, in this postmodern era, mindset and values of people's lives have changed a lot toward the globalization paradigm hence no longer uphold sacred values in a social system. Poor community preparedness, especially among women attests to the extent to which local knowledge, which is based on the sensitivity in feeling the natural signs, is diminishing.

\subsection{Adaptive Capacity}

The primary focus of this paper is adaptive capacities that contribute to the emergence of community resilience. Community resilient refers to the time required the system to return to equilibrium once displaced (Bodin \& Wiman, 2004). Across this definition, resilience then conceptualizes as an ability and adaptability (Pfefferbaum, Reissman, Pfefferbaum, Klomp, \& Gurwitch, 2005). Community has the potential to function effectively and adapt successfully after disaster occurs. However, this condition could only be reached if the community has the capacity of resilience. Capacity of resilience occurs when resources are sufficiently robust, redundant, or rapid to buffer or counteract the effects of the stressor and adapts to the altered environment which manifest in wellness (Noris, Steven, Pfefferbaum, Wyche, \& Pfefferbaum, 2008). Pelling (2003, p. 48) adds that the ability of individual and community to cope with or adapt to hazard stress would be formed the resilience community. Further Dovers and Handmer (1992, p. 270) distinguish societal resilience into three levels. They are resilience 
through resistance to change; resilience through incremental change at the margins; and resilience through openness and adaptability.

The concept of resilience has been applied to describe the adaptive capacity of individual and community. Adaptive capacity is a linking process to a positive trajectory and adaptation after a disturbance, stress and adversity to create community resilient. Gunderson (2000) defines adaptive capacity as the property of the ecosystem that describes changes in stability landscapes and resilience. Noris et al (2008) add that adaptive capacities are resources with dynamic attributes, a point to which individual or community will return quickly. The concept of community resilience is thus intimately linked to the concept of adaptive capacity which focused on four primary sets of networked resources, which are economic development, social capital, information and communication, and community competence (Figure 1).

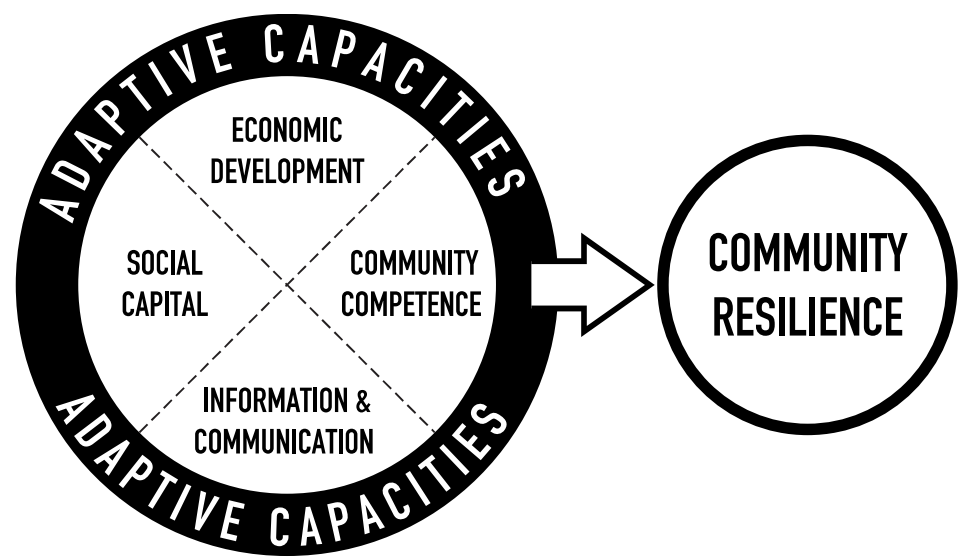

Figure 1. Networked Resources of Adaptive Capacity Source: Developed from Noris et al (2008)

Firstly is economic development. Community resilience depends much on the diversity of economic resources. The capacities to distribute post-disaster resources to those who most need are important for community resilience. The parameter of economic development such as stability of livelihoods, equitable distribution of income and the availability of raw materials, physical capital, accessible housing, health services, schools, and employment opportunities would create the essential resource base of a resilient community. Secondly is social capital. The basic idea of social capital according to Lin (2001) is that individuals invest, access, and use resources embedded in social networks to gain return. It can also be defined as the aggregate of the actual or potential resources that are linked to possession of a durable network of relationships (Bourdieu, 1986). Social capital plays a significant role in forming the community resilience because it functions as an attitude of bonding (trust and belonging) and shared values with other members of one's group (Perkins, Hughey, \& Speer, 2002, p. 37). By having sense of community, sense of connection and mutual concerns among others, it is assumed to be a dimension of community capacity. Thirdly is information and communication. Information and communication are the primary resource in technical and organizational systems that enables adaptive performance (Comfort, 2005) as well as essential for the nature of community resilience and capacity (Pfefferbaum et al., 2005) . These resources create common meanings, understandings and the provision of opportunities for community to articulate needs, views, and attitudes. Fourthly is community competence. Communities must be able to learn and identify potential risk that might be threaten them and work together to solve problems. Longstaff (2005) argued that the capacity to acquire trusted and accurate information, to reflect on that information critically, and to solve emerging problems is important for community resilience. Community competence relates to collective action, decision-making, capacities that stem from collective efficacy and empowerment (Noris et al., 2008).

\section{Result and Discussion}

\subsection{Networked Resources of Adaptive Capacity: Economic Development}

Post disaster condition has created an opportunity for women to start their own businesses which has diversified economic resources at their disposal. Research findings show that after disaster, there were hardily found any women who suffer from unemployment in Bantul and Sleman. Most women run small businesses dealing in 
batik making, traditional foodstuffs, leather or bamboo crafting. However, in Sleman, women chose to work in the informal sector activities such as serving as porters. On the other hand, damage and destruction left in the wake of the disaster, had an effect on the way businesses are run by women in both places. This is especially so with respect to the availability of raw materials and workshop, difficulty in finding new markets, and shortage of capital. To overcome such barriers, women have reacted by adopting the strategy of marketing their products using online coupled with forming a business group which is the requirement form them to eligible for government and private assistance. This further confirms what Holman and Silver (1998) and Schwarzer, Hahn and Schoder (1994) noted to the effect that the higher the frequency of exposure to catastrophic events a community experiences, the stronger and resilient that community becomes in adapting to any form of change and challenges that occur. However, disaster resilient women in Sleman are still on the second level of disaster resilient communities, which according to Tobin (1999) is a community that still requires attention from others to survive.

Women resilience to disasters is also attributable to cultural factors that make them feel shamed if they do not engage in work or just stay at home without contributing to family wellbeing. Seeing the success of other women and acquiring training, women in Sleman expressed strong motivation to become successful persons who have the ability to overcome disaster related problems. The positive response of the community has created a coterie of resilient women in facing the disaster. The resilience women from the disaster in Sleman are discernible from their acceptance to disasters, adaptive and ability to use internal resources and their expertise to manage the challenges and changes that occur after a disaster.

The high poverty rate prior to disasters, playing subservient roles in the labor force, largely employed in informal sector, land rights regime that was biased against them, and shouldered extensive domestic responsibilities, meant that women in the two districts were economically vulnerable long before natural disasters occurred. Prior to the advent of the disaster, the majority of women in this study in both Sleman and Bantul, managed a business or were employees in other economic activities. They worked as batik or leather craftswomen in Wukirsari village, Bantul, while in Sleman, women worked as dairy farmers, selling their milk to cooperatives in the area. Unfortunately, disasters disrupted their trades and markets, destroyed productive resources and infrastructure, and made life more difficult for workingwomen thrive through the crisis. To that end, restoration of economic resources and capacities of women are crucial for long-term recovery even as they continue to consider their roles as wives, mothers and community members.

\subsection{Social Capital}

In disaster situations, where access to many resources is compromised, social capital becomes a more significant element in recovery. Social capital, as it is used here, follows Lin (2000, p. 786), who defines it as the "investment and use of embedded resources in social relations for expected returns." An individual's participation and investment in social interactions and reciprocal relations with other individuals establishes a person's "social network," within which social capital is created, held and accessed. The breadth and strength of social networks is highly variable, and can be influenced by numerous factors. For example, gender, household composition, and economic circumstances all have an effect on the way a person relates to others to create, maintain and utilize social networks and associated social capital.

This study focused on social capital from the vantage point of the existence and role of local institutions, values and norms that exist in the community and response to disasters. At the institutional level, many local institutions are in place in both villages. Most women are actively involved in social groups. Thus, this social group has become a local institution that serves as a strategic medium for exchanging experiences and information, including information on disasters. It should be noted that although obtaining information through one's social network is a daily practice for most people, the importance of a person's social network increases in circumstances where usual methods of information sharing and resource obtainment are no longer available. Disaster situations may impose stress on these networks because such events often affect broad areas and large numbers of people who would otherwise be networked together socially. Thus, social capital developed through informal associations can prove more viable when the integrity of formal systems is compromised.

Besides, the existence of social relations among citizens is also another manifestation of social capital. The intensity of social relations between people is a good measure of the level of social capital in the community. Culture in rural communities has an impact on the intensity of social interactions within the community. Within a relatively homogeneous society, culture, religion and employment naturally lead to the formation of social relations. Study results showed that social group meetings were held frequently to discuss various things about lives of members as well as the availability and distribution of childcare responsibilities after disaster. Informal 
meetings that take place between members of the community may be able to strengthen the potential of understanding and knowledge of citizens about disaster information. Moreover, the process of delivering information about the disaster increases the effectiveness of interaction among community members. In any case, informal atmosphere and casual relationships increases the understanding and acceptability of citizens about disaster information.

Given that post-disaster settings underscore the importance of social inequalities, research results point to the fact that inequalities are likely to affect a person's capabilities and strategies to use social capital after a disaster (Cutter \& Emrich, 2006; Lin, 2000). Dynes (2006, p. 23) identifies social capital as an active resource in disaster recovery and, "since social capital theory links the consequences of individual action to social resources, such a linkage holds the possibility of explaining individual 'trauma' and individual resilience to disaster." Study results confirmed the above findings. The value of gotong royong, which involves working voluntarily among community members, in both Wukirsari and in Kepuharjo, is very strong. The contribution of social capital in Bantul's disaster recovery program, for instance, can be gleaned from the practices of the community that involved working voluntarily in building houses and infrastructure facilities (Kusumasari \& Alam, 2012). However, leading social capital theorists such as Bourdieu (1986), Coleman (1990), and Lin (2001) demonstrate that, while it can be a useful resource, social capital is not equally available to all people because it functions through social systems of inequality. Hence, forms of social capital that found in this research play an important role in a post-disaster situation.

\subsection{Information and Communication}

One way to look at the role of women in disaster management is to determine the extent to which women understand and have the ability to categorize conditions in areas where they live as hazardous or not. The results of this research showed that more than 80 percent of women in Sleman were aware of the fact that their area was prone to disasters and also know the signs of disaster. In contrast, Bantul produced results that were the opposite. The knowledge of women about the signs of disaster continues to be very low even though they realize that the area where they live is a disaster-prone area.

The different level of knowledge between women in Sleman and Bantul is attributable to the different nature of the disaster that occurred. Sleman women are accustomed to Merapi a eruption disaster, which is periodic, in nature. The experience women have gained in facing eruptions has enabled Sleman women to acquire learning about the warning signs that appear prior to every eruption. In addition, the government has overtime strengthened the capacity of local communities or other organizations that are concerned about the danger of Merapi. In this study, results showed that the involvement of women in Bantul and Sleman, especially in disaster management is still very low. Women participation in some activities, such as conducting vulnerability analysis, disaster response and emergency response training was below 4 percent. Women participation was only relatively high in the activity that related to the provision of logistics for disasters, hovering about 10 percent. However, it is worth noting that mitigation activities that are designed by local authorities involve both men and women. This is particularly so with respect to emergency response training in Sleman that achieved $100 \%$ of participation rate and the designing of the evacuation route map in Bantul, which involved both men and women. That said, male involvement in disaster mitigation, especially in the provision of facilities and infrastructure for disaster management in Sleman and designing evacuation route map in Bantul, was nearly 40 percent.

Women participation in disaster management, is one the one of the important factors that determines the influence they have on the form, shape, and nature of disaster management. Lessons learned by women in Bantul and Sleman from their experiences in natural disasters has become a vital source of awareness to enhance the capacity of women to manage disasters, including equipping themselves with information on disaster. Do women and men obtain information differently? Based on various studies, it was found that adult men, teenage boys, teenage girls, adult women, the elderly, and children are the core of the dissemination of information, socialization of disaster and mitigation activities, as well as disaster response (Fatimah, 2008). Exploring the experience of women in both sub-districts, Wukirsari, Bantul or Kepuharjo, Sleman, shows that access to information, dissemination, and knowledge is closely related to the division of space and roles between gender and age. Adult male who have more roles in public spaces as well as considered to have higher physical mobility, have more opportunity to access information about the disaster and are more engaged in disaster mitigation activities. Thus, male gender is closely related to disaster management in such issues as evacuation, simulation, and emergency response activities

This research has provided valuable lessons learned with respect to the importance of involving women in disaster management in general and disaster preparedness and mitigation activities, in particular. Firstly, women 
are well versed with their area and have the ability to learn to undertake social analysis, especially on demographics. Secondly, women were able to learn ways of identifying the risks that exist in the area where they live and it is hoped that women can help children to become aware and do various activities that contribute to reducing disaster risks. Thirdly, active involvement of women in disaster management activities enables them to internalize lessons they learn from those activities into their subconscious selves. Therefore, in the event of a disaster, women in the location can quickly decide the right way to escape. Lastly, the involvement of women helps to reduce the negative post disaster effects.

\subsection{Community Competence}

One concern that creates risky conditions for women is "household size and structure and power relations in kinship and marriage especially in contexts of divorce, desertion, widowhood and single mothering" (Enarson, 1998; p. 161). The responsibility of women for household members significantly influences their disaster work. This is more so if they are single household heads, which affects their decisions to prepare and to evacuate. Results of this study attested to this fact. Women reported spending little time to help in cleaning up the community and instead, focused more on their households. In addition, women reported playing greater role in disaster preparedness than men. Women explained having the task of developing household disaster action plans and practicing them more often than men, while men reported higher rates of understanding their community's warning systems and keeping up with the weather reports.

Survey results also portrayed women's capacity to anticipate disasters. More than 75 percent of women chose to seek safety for themselves and their family rather than property and their livestock. In fact, what happened in Sleman was that the long duration of Merapi eruption, created uncertainty for the livelihoods of the displaced persons, both their lives in displaced camps and abandoned property. Livestock is an important property for the displaced persons as most of them earn a living from farming. People who live on the slopes of Merapi are willing to risk their lives in order to ensure the safety of their livestock. To that end, the government was concerned about this phenomenon, as it had the potential danger to increase the number of casualties from the eruption. As a response, on 5 November 2010, the central government issued a circular that contained commitment to buy all the cattle in all areas affected by the disaster as well as disaster-prone areas. The findings of this research also highlight the extent to which previous disaster experience and women 'inherited' capabilities have significant impact on disaster recovery. The pain of suffering from the adverse effects of disasters has contributed to the creation of women's inner strength and physical resiliency.

\section{Conclusion}

In any disaster event, women fall into groups of people who face various vulnerabilities: physical, economic, social, and environmental vulnerability. However, the frequent exposure to natural disasters, which women face, has shaped them to become stronger and more resilient in adapting to any form of change and challenges that occur. This research has elaborated the adaptation capacity of women in Bantul and Sleman, Indonesia, viewed with respect to contribution to economic activities, social capital, dissemination of information and communication and enhancing community wellbeing.

In terms of economic development, this study precisely shows that women in both places are significant economic actors who have businesses that contributed to mitigating the shock of the disaster on incomes of their families. In fact, women generated income that contributed most to livelihoods of their families.

In the context of social capital, Violanti, Paton and Dunning (2000) identified the variables that are capable of predicting the resilience of a community to disaster. The variables include, having sense of community, coping ability, self efficacy and social support. In terms of having a sense of community, women in Bantul and Sleman have an attachment to their neighborhood, which is reflected in helping and working with others in providing logistics. Their coping ability is reflected in the way women develop new techniques for batik making, create new markets using an online system, and having informal jobs that are completely different from their previous ones. By running their own small businesses that support almost 80 percent of their family income, inevitably raised women's self-efficacy. Women in both locations have become less dependent on men. Moreover, the behavior of not remaining silent amidst the crisis is also a form of resiliency of women to the disaster. Social support has also played an important role in making the community resilient to the disaster. This is because women in both locations received a lot of support from the government, NGOs, and the private sector. The assistance was vital for supporting women to move on from crisis.

In terms of information and communication, women can serve as social marketers. This entails the involvement of women and teaching them disaster related knowledge as early as possible. Despite the fact that women belong to the category that is vulnerable to disasters, they can serve as agents of change. Thus, empowering women 
enhances their ability to survive whenever disasters occur, while at the same time protecting themselves and people around them from disasters. The expectation is that the involvement of women in various mitigation and disaster response activities should minimize the adverse effects of a catastrophic event.

In the context of community competence, the experience of women in Bantul and Sleman who have been exposed to the disaster has enabled them to become more sensitive and concerned about signs of disaster. The combination of many programs run by the government and NGOs in mitigation and preparedness, has also contributed to enhancing the knowledge of women about disaster education. Environmental vulnerability also affects the vulnerability of a society. In the sense that women who live on the slopes of Merapi will always be living in danger of eruption, while those who live in Bantul will always face vulnerability to earthquakes, fires, floods or landslides. The awareness of women who live in disaster-prone areas should be addressed by, for example, building earthquake-resistant residences such as those in Bantul. With respect to all aspects of vulnerability, women in Wukirsari village, Bantul and Kepuharjo village, Sleman do not fall into the category of women who are vulnerable, but on the contrary, women in both regions, have demonstrated their ability to adapt to disasters. This is very much in line with Pelling (2003), who notes that women's ability to cope with natural disasters depends on their capacity to survive. In such situation, individuals either have to return to previous conditions that require integrating some new activities into the 'old' or adapting to the new environment that ensues in the wake of the disaster. Women in Bantul and Sleman attest to being empowered and demonstrate high self-esteem which qualities are reflected in their skills, expertise, and doing new jobs that are starkly different from those they had prior to the disaster. Moreover, the ability to generate income for their families has lessened the dependency of women on men.

\section{Acknowledgment}

The author would like to extend her gratitude to Dr. Partini and Dr. Hempri Suyatna of the Faculty of Social and Political Sciences Gadjah Mada University, Indonesia for their valuable advice in conducting collaborative research titled Women Resilient to Disaster in Yogyakarta

\section{References}

Adger, N., Brooks, N., Bentham, G., Agnew, M., \& Eriksen, S. (2004). New Indicators of Vulnerability and Adaptive Capacity. Norwich: Tyndall Centre for Climate Change Research.

Bodin, P., \& Wiman, B. (2004). Resilience and Other Stability Concepts in Ecology: Notes on their Origin, Validity, and Usefulness. ESS Bulletin, 2.

Bourdieu, P. (1986). Forms of Capital. In J. G. Richardson (Ed.), Handbook of Theory and Research for the Sociology of Education. New York: Greenwood Press.

Coleman, J. (1990). Foundations of Social Theory. Cambridge: Belknap Press.

Comfort, L. K. (2005). Risk, Security and Disaster Management. Annual Review of Political Science, 8(1). http://dx.doi.org/10.1146/annurev.polisci.8.081404.075608

Covington, J., \& Simpson, D. M. (2006). An Overview of Disaster Preparedness Literature: Building Blocks for an Applied Bay Area Template. Louiseville: Center for Hazards Research and Policy Development.

Cutter, S. (1996). Vulnerability to Environmental Hazards. Progress in Human Geography, 20(4). http://dx.doi.org/10.1177/030913259602000407

Cutter, S. L., \& Emrich, C. T. (2006). Moral Hazard, Social Catastrophe: The Changing Face of Vulnerability along the Hurricane Coasts. Annals of the American Academy of Political and Social Science, 604(1). http://dx.doi.org/10.1177/0002716205285515

Dovers, S. R., \& Handmer, J. W. (1992). Uncertainty, Sustainability and Change. Global Environmental Change, 2(4). http://dx.doi.org/10.1016/0959-3780(92)90044-8

Dynes, R. (2006). Social Capital: Dealing with Emergencies. Homeland Security Affairs, 2(4).

Enarson, \& Morrow. (Eds.). (1998). The Gendered Terrain of Disaster: Through Women's Eyes. Florida: Laboratory for Social and Behavioural Research, Florida International University.

Fatimah, D. (2008). Gender in Disaster Management: The Case of Merapi Mountain. Indonesia: Office of Women Empowerment- APEC Gender Focal Point.

Fothergill, A. (1998). The Neglect of Gender in Disaster Work. In E. Enarson, \& B. H. Morrow (Eds.), The Gendered Terrain of Disaster. Westport: Praeger. 
Gunderson, L. (2000). Ecological Resilience in Theory and Application. Annual Review of Ecology and Systematics, 31. http://dx.doi.org/10.1146/annurev.ecolsys.31.1.425

Holman, E. A., \& Silver, R. C. (1998). Getting Stuck in the Past: Temporal Orientation and Coping with Trauma. Journal of Personality and Social Psychology, 74. http://dx.doi.org/10.1037/0022-3514.74.5.1146

Kusumasari, B., \& Alam, Q. (2012). Local Wisdom-Based Disaster Recovery Model in Indonesia. Disaster Prevention and Management, 21(3). http://dx.doi.org/10.1108/09653561211234525

Lambdin, R. T., \& Lambdin, L. C. (2000). Encyclopedia of Medieval Literature. London: Fitzroy Dearborn Publishers.

Lin, N. (2000). Inequality in Social Capital. Contemporary Sociology, 29(6). http://dx.doi.org/10.2307/2654086

Lin, N. (2001). Social Capital. New York: Cambridge University Press. http://dx.doi.org/10.1017/CBO978051 1815447

Longstaff, P. (2005). Security, Resilience, and Communication in Unpredictable Environments. New York: Syracuse.

Mbithi, P. M., \& Wisner, B. (1973). Drought and Famine in Kenya: Magnitude and Attempted Solutions. Journal of Eastern African Research and Development, 3.

Noris, F. H., Steven, S. P., Pfefferbaum, B., Wyche, K. F., \& Pfefferbaum, R. L. (2008). Community Resilience as a Metaphor, Theory, Set of Capacities and Strategy for Disaster Readiness. Am J Community Psychol., 41. http://dx.doi.org/10.1007/s10464-007-9156-6

Pelling, M. (2003). The Vulnerabilities of Cities: Natural Disasters and Social Resilience. London: Earthscan.

Perkins, D., Hughey, J., \& Speer, P. (2002). Community Perspectives on Social Capital Theory and Community Development Practice. Journal of the Community Development Society, 33. http://dx.doi.org/10.1080/ 15575330209490141

Pfefferbaum, B., Reissman, D., Pfefferbaum, R. L., Klomp, R., \& Gurwitch, R. (2005). Building Resilience to Mass Trauma Events. In L. Doll, S. Bonzo, J. Mercy, \& D. Sleet (Eds.), Handbook on Injury and Violence Prevention Interventions. New York: Kluwer Academic Publishers.

Reardon, T., \& Matlon, P. (1989). Seasonal Food Insecurity and Vulnerability in Drought-Affected Regions of Burkina Faso. In D. E Sahn (Ed.), Seasonal Variability in Third World Agriculture: The Consequences for Food Security. Baltimore: International Food Policy Research Institute/Johns Hopkins University Press.

Scanlon, J. (1998). The Perspective of Gender: a Missing Element in Disaster Response. In E. Enarson, \& B. H. Morrow (Eds.), The Gendered Terrain of Disaster: Through Women's Eyes. Westport: Praeger Publishers.

Schwarzer, R., Hahn, A., \& Schoder, H. (1994). Social Integration and Social Support in a Life Crisis: Effects of Macrosocial Change in East Germany. American Journal of Community Psychology, 22. http://dx.doi.org/10.1007/BF02506899

Shiva, V., \& Mies, M. (1993). Ecofeminism. London: Zed Books.

Snape, D., \& Spencer, L. (2003). The Foundations of Qualitative Research. In J. Ritchie, \& J. Lewis (Eds.), Qualitative Research Practice. London: Sage Publications.

Tierney, K. J., Lindell, M. K., \& Perry, R. W. (2001). Facing the Unexpected: Disaster Preparedness and Response in the United States. Washington D.C: Joseph Henry Press.

Tobin, G. A. (1999). Sustainability and Community Resilience: the Holy Grail of Hazards Planning. Environmental Hazards, 1. http://dx.doi.org/10.1016/S1464-2867(99)00002-9

Violanti, J. M., Paton, D., \& Dunning, C. (2000). Post-Traumatic Stress Intervention: Challenges, Issues and Perspectives. Springfield: Charles C. Thomas.

White, B. (2007). Disaster Preparedness in the United States. Arcata: Humboldt State University.

\section{Copyrights}

Copyright for this article is retained by the author(s), with first publication rights granted to the journal.

This is an open-access article distributed under the terms and conditions of the Creative Commons Attribution license (http://creativecommons.org/licenses/by/3.0/). 